\title{
Effect of weight reduction in obese patients diagnosed with knee osteoarthritis: a systematic review and meta-analysis
}

\author{
Robin Christensen, Else Marie Bartels, Arne Astrup, Henning Bliddal
}

Ann Rheum Dis 2007;66:433-439. doi: 10.1136/ard.2006.065904

This review aims to assess by meta-analysis of randomised controlled trials (RCTs) changes in pain and function when overweight patients with knee osteoarthritis (OA) achieve a weight loss. Systematic searches were performed and reference lists from the retrieved trials were searched. RCTs were enclosed in the systematic review if they explicitly stated diagnosis of knee $\mathrm{OA}$ and reported a weight change as the only difference in intervention from the control group. Outcome Measures for Arthritis Clinical Trials III outcome variables were considered for analysis. Effect size (ES) was calculated using RevMan, and meta-regression analyses were performed using weighted estimates from the random effects analyses. Among 35 potential trials identified, four RCTs including five intervention/ control groups met our inclusion criteria and provided data from 454 patients. Pooled ES for pain and physical disability were $0.20(95 \% \mathrm{Cl} 0$ to 0.39$)$ and $0.23(0.04$ to 0.42$)$ at a weight reduction of $6.1 \mathrm{~kg}(4.7$ to $7.6 \mathrm{~kg})$. Meta-regression analysis showed that disability could be significantly improved when weight was reduced over $5.1 \%$, or at the rate of $>0.24 \%$ reduction per week. Clinical efficacy on pain reduction was present, although not predictable after weight loss. Metaregression analysis indicated that physical disability of patients with knee OA and overweight diminished after a moderate weight reduction regime. The analysis supported that a weight loss of $>5 \%$ should be achieved within a 20 -week period-that is, $0.25 \%$ per week.

See end of article for authors' affiliations

Correspondence to: Professor $\mathrm{H}$ Bliddal, The Parker Institute, $\mathrm{H}: \mathrm{S}$ Frederiksberg Hospital, DK2000 Frederiksberg, Denmark; henning.bliddal@fh.hosp. dk

Accepted

21 December 2006

Published Online First

4 January 2007
B eing overweight is an important factor in osteoarthritis (OA), and obese subjects are at high risk of developing OA in the knee. ${ }^{1}$ The average body weight of the increasing number of elderly people has steadily risen in recent years. ${ }^{2}$ The obesity problem appears across multiple age groups, ${ }^{3}$ and there is reason to believe that the obesity-related knee OA will increase in both numbers and severity. ${ }^{5}$ Obesity must be taken seriously in any discussion concerning health issues, ${ }^{6}$ including that of the bone and joints. ${ }^{7}$

Current European evidence-based recommendations for the management of knee OA, devised by the European League Against Rheumatism, include weight loss as a sensible option in overweight patients with knee OA. However, this recommendation is primarily supported by expert opinion $^{8}$; meta-analysis of randomised controlled trials (RCTs; ie, category la evidence) is yet to be undertaken.
The objective of this systematic review and meta-analysis was to assess and quantify whether the clinical benefits (changes in pain and functional disability $)^{9}$ are evident in patients with knee OA after weight loss. Applying the rules of evidence-based medicine, ${ }^{10}{ }^{11}$ with focus on quality (ie, magnitude and intensity) of the intervention, ${ }^{12}$ we aimed to meta-analyse ${ }^{13}$ and present doseresponse efficacy estimates of weight loss in obese patients with knee OA.

\section{METHODS}

\section{Retrieval of published studies}

A systematic literature search was carried out to identify and locate all controlled and preferably randomised trials dealing with the effects of weight loss on symptoms associated with knee OA. ${ }^{14}$

The following bibliographic databases were searched: MEDLINE (1966-April 2006) via PubMed, EMBASE (1980-April 2006) and CINAHL (1982-April 2006) via WebSpirs, Web of Science (1945-54)-April 2006), and Scopus (1966May 2006), to identify all clinical trials relating obesity to OA. Other databases searched were The Cochrane Musculoskeletal Group's trial's register and The Cochrane Controlled Trial's register. The following three areas were combined in the study as medical subject headings/keywords with all subheadings and as free text: (1)OA, and where possible OA of the knee; (2) controlled studies; and (3) weight loss/gain/changes or diet or antiobesity agents or exercise. The lists of references of retrieved publications were manually checked to add any citations missed by the electronic searches. Abstracts from scientific meetings were included if enough information was available in the abstract. No language restrictions were applied. The search strategy was deliberately broad, and the actual selection process was therefore done from these retrieved references by assessing each reference from abstract and publication type. The retrieved references at this point were recognised as potentially possible studies.

\section{Inclusion and exclusion criteria}

Randomised controlled trials (RCTs) that fulfilled the criteria described below were enclosed in the systematic review, and accordingly in the formal meta-analysis, providing evidence category la based on gathered evidence category $1 \mathrm{~b} .{ }^{10}$

Abbreviations: $E S$, effect size; $\mathrm{OA}$, osteoarthritis; $\mathrm{RCT}$, randomised controlled trial; SMD, standardised mean difference 


\section{Selection criteria}

Participants were females and/or males with an explicitly stated diagnosis of $\mathrm{OA}$ of the knee. In case of studies reporting a patient population of mixed clinical characteristics (eg, both hip and knee OA), the subgroup results from knee OA only had to be extractable to fulfil the inclusion criteria. Any intervention where a weight change was reported explicitly, whether it was intentional or unintentional, was accepted. The weight change (ie, reduction) had to be the only difference from the defined control group. Any concomitant treatments (medication, exercise, behavioural therapies, etc) had to be identical in the treated and the control group, ensuring that any clinical benefits were caused by a difference in change of body weight, independently of any possible interactions that might have influenced the outcome of OA. Criteria for inclusion of trials were (a) subjects with a diagnosis of OA of the knee, as specified earlier; (b) RCT design; (c) specification of comparative treatment; and (d) published data on relevant outcome measures.

\section{Quality assessment}

Study quality was scored independently by two of the reviewers (RC, HB), using the "Instrument to Measure the Likelihood of Bias", giving points for each answer, as proposed by Jadad et al. ${ }^{15}$ By definition, the scores ranged from 0 to 5 , with higher scores indicating less likelihood of bias in the results. ${ }^{15}$

\section{Data extraction and analyses}

Data from the trials were extracted by two reviewers (RC and EMB). A standard data extraction form was developed to use for data collection. The following information was systematically extracted for each of the $\mathrm{k}$ randomised trials: characteristics of the study population: age, number of participating females $/($ males + females $) \times 100 \%(\% \mathrm{~F})$, treatment period (duration time), primary endpoint, intention-to-treat (yes/no), quality score (0-5; as presented above), and body mass index at baseline (inclusion). From each of the $\mathrm{k}$ trials (and substudies, if any study reported mutually independent two-group comparisons within the same article), we extracted the following numbers and estimates by group ( $\mathrm{T}$, treatment and $\mathrm{C}$, control, respectively): number of patients in the group (n); change in the outcome measure of interest within the treatment group (the mean change, $\Delta$ ); $\mathrm{SD}_{\Delta}$ in the outcome measure of interest within each group (corresponding to the mean change within the group).

Change scores were used, as some of the studies were small and showed baseline differences in outcome scores between the allocation groups. When the required data in the studies were not presented clearly, a standardised extraction recalculation technique was used, as recommended by The Cochrane Statistical Methods Group. ${ }^{16}$ To enable the use of metaregression analyses, the simultaneous mean changes in body weight $(\%)$ in each of the two groups per ith substudy $\left(\Delta\right.$ Weight $_{\mathrm{Ti}}$ and $\Delta$ Weight $_{\mathrm{Ci}}$, respectively) were extracted, together with the SDs of the changes (or calculated assuming the same data distribution as the absolute change, in $\mathrm{kg}$ ).

\section{Outcome measures}

The Outcome Measures for Arthritis Clinical Trials III outcome variables ${ }^{9}$ were considered for analysis: pain, self-reported disability and patient global evaluation. Secondary outcomes were "weight change" from baseline reported as mean weight loss (in $\mathrm{kg}$ or \%).

\section{Statistical analyses}

As the studies used a variety of continuous data scales to evaluate clinical outcomes, a unit-less measure of treatment effect size (ES) was applied to pool the results across the multiple controlled trials. As recommended by the Cochrane Collaboration, ${ }^{16}$ we used the standardised mean difference (SMD) as summary measure, which is applicable for interpretation as the ES originally proposed by Cohen. ${ }^{17}$ Clinically, an ES of 0.2 is considered small, 0.5 as moderate (and would be recognised clinically) and $>0.8$ as large. ${ }^{8}$ Accordingly, the ES (SMD) that we used was Hedges' adjusted g value, which is very similar to Cohen's d value, although with an adjustment for small sample bias. ${ }^{18}$ To pool the mean different weight reduction of individual study group, the weighted mean difference was applied. ${ }^{19}$ Random effects meta-analysis ${ }^{20}$ was used if the studies were heterogeneous, for which the Cochran $\mathrm{Q}$ test was used to assess the degree of heterogeneity ${ }^{21}$; the $\alpha$ risk for this analysis is set to $0.1(\mathrm{p}<10 \%) .{ }^{1622}$ Quantification of the effect of heterogeneity was assessed by means of $\mathrm{I}^{2}$, which ranges from $0 \%$ to $100 \%$; $\mathrm{I}^{2}$ shows the percentage of total variation across studies due to heterogeneity, and may be used to assess the consistency of evidence. ${ }^{23}$ These analyses were carried out using the software provided by the Cochrane Collaboration, Review Manager (RevMan V.4.2). ${ }^{18}$ For further illumination of the quality (ie, magnitude and intensity) of the intervention, ${ }^{12}$ we applied dose-response efficacy estimates following meta-regression analyses, with two subsequent a priori defined weight change differences (\% point weight change as magnitude and \% point weight change per week as intensity, respectively) as independent variables. Metaregression analyses should be weighted to take account of both within-trial variances of treatment effects and the residual between-trial heterogeneity (ie, heterogeneity not explained by the covariates in the regression). We therefore applied the random effects meta-regression, ${ }^{24}$ using the individual study weight (based on the inverse variance) following the random effects model presented by DerSimonian and Laird. ${ }^{20}$ All metaregression analyses were calculated using SAS statistical package V.8.

\section{RESULTS}

\section{Search of published reports}

Thirty-five studies were retrieved from the literature search. Figure 1 shows the stages of this selection process, as recommended in the Quality of Reporting of Meta-analyses statement. ${ }^{13}$ Following the selection process, only four studies met the inclusion criteria.

Out of the 35 possible studies, ${ }^{25-59}$ two were lacking a proper control group ${ }^{25} 26$; one of the studies was elegantly controlled but not randomised and therefore excluded. ${ }^{27}$ Four further studies did not give results based on patients with knee OA. ${ }^{28-31}$ However, looking at obesity or overweight and the effect of these conditions on OA, seven studies, when studied closely, looked at the effects of obesity on developing $\mathrm{OA}^{32-38}$ At abstract and keyword level, it was not always possible to assess whether weight loss or other treatment is the parameter studied, or whether the outcome measure was pain or physical function. By closer study, eight studies were eliminated from our potentially possible studies for analysis due to not concerning weight loss and effect on physical function and pain. ${ }^{39-46}$ Out of the 13 studies left in our collection, three did not assess the effect of weight loss alone, ${ }^{47-49}$ and six studies were either part of other studies or follow-up on other studies. ${ }^{50-55}$

At the end of the selection process, four randomised, controlled studies were included in the final meta-analysis (table 1). ${ }^{56-59}$ It was possible to extract two independent comparisons from the study by Messier et al (four-arm RCT). ${ }^{58}$ This study was therefore handled as two mutually independent publications: Messier 2004a and Messier 2004b. ${ }^{58}$ In some of the studies, no significant differences in body weight change 


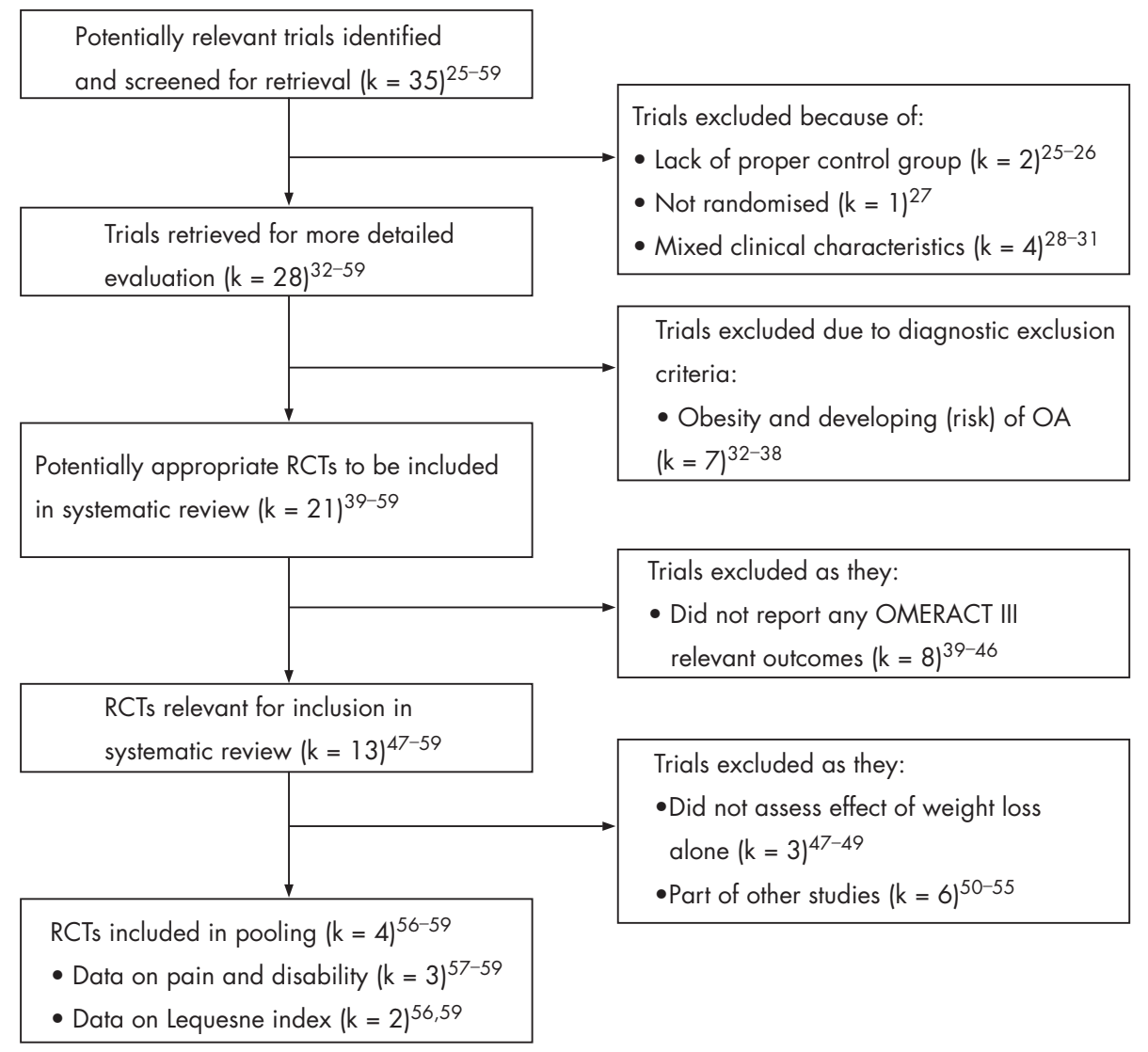

Figure 1 Flow of randomised controlled trials included in the systematic review. RCT, randomised controlled trial.

were apparent among the various dietary interventions, and accordingly a regression analysis considering dosage seems reasonable. ${ }^{12} 60$

\section{Efficacy}

Pain

Pooling the data from the trials reporting pain as an explicit outcome $^{57-59}$ produced a weighted pooled ES of 0.2 (95\% CI 0 to $0.39 ; \mathrm{p}=0.05$ ) favouring weight loss (presented in fig 2A). The result is based on 417 randomised patients, following a significant (group mean different) weight loss of $6.1 \mathrm{~kg}$ (95\% CI 4.7 to $7.6 \mathrm{~kg} ; \mathrm{p}<0.001$ ). The weighted pooled ES is based on a fixed effect meta-analysis, as we assumed a reasonable homogeneity between study means $\left(\chi^{2}=5.69, \mathrm{p}=0.13\right.$, $\left.\mathrm{I}^{2}=47.2 \%\right)$.
Self-reported disability

Pooling the data from the trials reporting self-reported disability as an explicit outcome $e^{57-59}$ produced a weighted pooled ES of 0.23 (95\% CI 0.04 to $0.42 ; p=0.02$ ) favouring weight loss (presented in fig 2B). The result is based on 417 randomised patients following a significant group mean different weight loss of $6.1 \mathrm{~kg}$ (95\% CI 4.7 to 7.6 ; p<0.001). The weighted pooled ES is based on a fixed effect metaanalysis, as we assumed a reasonable homogeneity between study means $\left(\chi^{2}=4.97, \mathrm{p}=0.17, \mathrm{I}^{2}=39.7 \%\right)$.

\section{Lequesne indices}

Pooling the data from the trials reporting the (global) Lequesne index as an explicit outcome ${ }^{56} 59$ produced a non-significant, inconsistent weighted pooled ES of 0.58 (95\% CI -0.4 to 1.56 ;

Table 1 Characteristics of randomised controlled trials included in the meta-analysis

\begin{tabular}{|c|c|c|c|c|c|c|c|c|c|c|}
\hline \multirow[b]{2}{*}{ Study } & \multirow[b]{2}{*}{ Substudy } & \multirow[b]{2}{*}{ QS } & \multirow[b]{2}{*}{$\begin{array}{l}\text { Intervention different } \\
\text { from control }\end{array}$} & \multirow[b]{2}{*}{ Duration } & \multirow[b]{2}{*}{$\begin{array}{l}\text { Mean age } \\
\text { (years) }\end{array}$} & \multirow[b]{2}{*}{$\begin{array}{l}\text { Sex (\% } \\
\text { female) }\end{array}$} & \multirow[b]{2}{*}{$\begin{array}{l}\text { Mean BMI } \\
\left(\mathrm{kg} / \mathrm{m}^{2}\right)\end{array}$} & \multicolumn{2}{|c|}{ No of subjects } & \multirow[b]{2}{*}{$\begin{array}{l}\text { Weight loss difference, } \\
\mathrm{kg}(95 \% \mathrm{Cl})\end{array}$} \\
\hline & & & & & & & & $\begin{array}{l}\text { Weight } \\
\text { loss group }\end{array}$ & $\begin{array}{l}\text { Control } \\
\text { group }\end{array}$ & \\
\hline Christensen $(2005)^{59}$ & - & 3 & $\begin{array}{l}\text { LED formula (3.4 MJ/day) } \\
\text { Nutrition class; CBT }\end{array}$ & 8 weeks & 63 & 89 & 36 & 40 & 40 & $-6.6(-8.3$ to -4.9$)$ \\
\hline Messier $(2000)^{57}$ & - & 2 & Nutrition class; CBT & 6 months & 68 & 71 & 36 & 12 & 9 & $-6.7(-11.1$ to -2.4$)$ \\
\hline Messier $(2004)^{58}$ & $a$ & 3 & Nutrition class; CBT & 18 months & 68 & 70 & 34 & 82 & 78 & $-3.5(-9.3$ to 2.3$)$ \\
\hline Messier $(2004)^{58}$ & b & 3 & $\begin{array}{l}\text { Nutrition class; CBT } \\
\text { (extra exercise) }^{*}\end{array}$ & 18 months & 69 & 74 & 34 & 76 & 80 & $-1.7(-7.7$ to 4.2$)$ \\
\hline Toda $(1998)^{56}$ & - & 2 & $\begin{array}{l}\text { Mazindol, } 0.5 \mathrm{mg} / \text { day } \\
\text { low-energy soup }\end{array}$ & 6 weeks & 63 & 100 & 29 & 22 & 15 & $-4.2(-5.1$ to -3.3$)$ \\
\hline
\end{tabular}

BMI, body mass index; CBT, cognitive behavioural therapy; LED, low-energy diet; QS, Jadad quality score.

*Both the weight loss group and the control group received this intervention in equal amounts. 
A

Christensen (2005)

Messier (2000)

Messier (2004a)

Messier (2004b)

Pooled fixed $(p=0.05)$

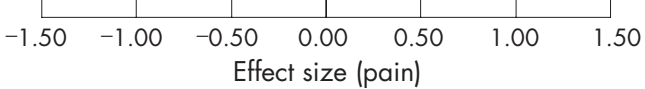

B

Christensen (2005)

Messier (2000)

Messier (2004a)

Messier (2004b)

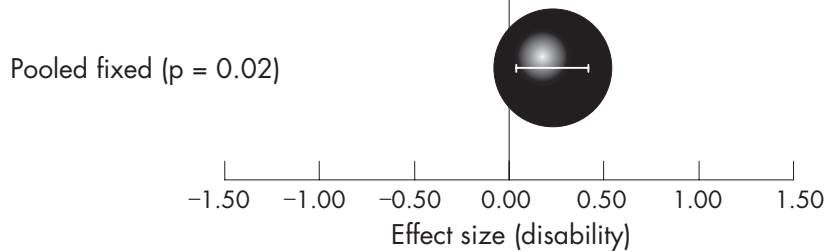

C

Christensen (2005)

Toda (1998)

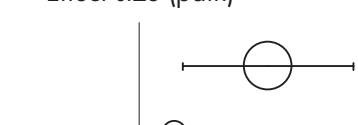

Pooled random $(p=0.25)$

Figure 2 Effect of weight reduction on pain, self-reported disability and the Lequesne index, respectively. The effect sizes (ES) are calculated as the $\operatorname{SMD}(95 \% \mathrm{CI})$. (A) $\chi^{2}=5.69, \mathrm{p}=0.13, \mathrm{I}^{2}=47.2 \%$; the pooled $\mathrm{ES}_{\text {fixed }}=0.20$ (95\% Cl 0 to $\left.0.39 ; \mathrm{p}=0.05\right)$. (B) $\chi^{2}=4.97, \mathrm{p}=0.17$ $\mathrm{I}^{2}=39.7 \%$; the pooled $\mathrm{ES}_{\text {fixed }}=0.23(95 \% \mathrm{Cl} 0.04$ to $0.42 ; \mathrm{p}=0.02)$. (C) $\chi^{2}=5.54, p=0.02, I^{2}=82.0 \%$; the pooled $\mathrm{ES}_{\text {random }}=0.58(95 \% \mathrm{Cl}-0.4$ to $1.56 ; p=0.25$.

$\mathrm{p}=0.25$ ) potentially favouring weight loss (presented in fig 2C); the result is based on 117 randomised patients following a significant group mean different weight loss of $4.7 \mathrm{~kg}$ (95\% CI 4 to $5.5 ; \mathrm{p}<0.001$ ). The weighted pooled ES is based on a random effect meta-analysis, as it was evident that there was heterogeneity between study means $\left(\chi^{2}=5.54, \mathrm{p}=0.02, \mathrm{I}^{2}=82.0 \%\right)$.

Dose-response

Changes in pain score and weight loss

As presented in fig 3A, body weight change (\%) in itself could not predict a significant change in pain score $\left(\mathrm{R}^{2}=19.7 \% ; \beta=0.029\right.$
$\left.\left(\mathrm{SE}_{\beta} 0.003\right)\right)$ as the upper $95 \%$ prediction interval never crossed the line indicating clinical efficacy $(\mathrm{ES}<0$ would indicate a reduction in pain compared with the control group). As presented in fig $3 \mathrm{~B}$, when the rate of weight change per week was used as independent variable, no consistent predictive model could be established for pain change with weight-change intensity on trial $\left(R^{2}=24 \% ; \beta=0.353\left(S_{\beta} 0.031\right)\right)$.

Changes in self-reported disability and weight loss As presented in fig 3C, body weight change (\%) in itself could predict a significant change in self-reported disability $\left(\mathrm{R}^{2}=75 \% ; \beta=0.067\left(\mathrm{SE}_{\beta} 0.002\right)\right)$ as the upper $95 \%$ prediction interval crossed the line indicating clinical efficacy $(\mathrm{ES}<0$ would suggest a reduction in disability compared with the control group). After solving the predicted "efficacy-equation" (upper prediction limit $\leqslant 0$ ), we calculated that if the magnitude of weight reduction was at least $5.1 \%$, it would predict a significant disability reduction. As presented in fig 3D, the weight change per week, used as independent variable (a surrogate for intensity), very consistently predicted disability reduction $\left(\mathrm{R}^{2}=92.2 \% ; \beta=0.81\left(\mathrm{SE}_{\beta} 0.012\right)\right)$. If the intensity of weight reduction was at least $0.24 \%$ per week, it would predict a significant disability reduction.

\section{DISCUSSION}

The major finding of the present meta-analysis was the association between improvement in physical disability and weight reduction, which showed that disability reduction could be predicted from weight loss. Previous category lA evidence support the use of weight reduction in the treatment of obese patients with OA, and operational considerations may be given on how these patients may reduce body weight. ${ }^{61}$ This study presents evidence-based estimates from a meta-analysis to support the use of weight-loss regimens in the clinical management of OA in clinical rheumatology.

The present meta-analysis shows that there are few highquality RCTs that can be used to provide evidence, and we have found a broad spectrum of heterogeneity in the interventions. ${ }^{12}$ Diversity across studies was substantial, and the reduction in both pain and self-reported disability was weak, although statistically significant, whereas no clinical effect could be detected using the Lequesne (global OA) disease index. Inspired by studies on heart disease and stroke, ${ }^{62}{ }^{63}$ we aimed to determine the dose-response effect applicable for clinical practice, when recommending weight reduction to patients with knee OA. The meta-regression models seemed inconsistent when the reduction in pain (ie, ES pain score; fig 3A,B) was used as dependent variable versus weight change. The predictability of effect on pain was questionable to use for clinical practice. By contrast, weight loss predicted (with great certainty $\mathrm{R}^{2} \geqslant 75 \%$ ) the patients' reduction in self-reported disability (ie, ES disability score; fig 3C,D). Based on our estimates, patients should achieve more than $5.1 \%$ weight loss, with a loss of at least $0.24 \%$ per week, to experience a significant reduction in disability. This would result in an $\mathrm{ES}=0.34$ and $\mathrm{ES}=0.19$, respectively.

The meta-regression analysis, which owing to the number of included randomised patients is considered "gold evidence", ${ }^{11}$ points towards recommending overweight patients with knee OA to reduce their body weight with at least $7.5 \%$, obtained with an intensity being at least $0.6 \%$ per week would result in an at least moderate clinical effect. Finally, if we apply the general dietary (public health) approaches to reduce body weight $^{64}$ to overweight patients with knee OA, using a rate of weight loss by 0.5 and $1.5 \mathrm{~kg} /$ week, ${ }^{61}$ the present meta-analysis shows that a $10 \%$ weight reduction will result in a moderate-tolarge clinical effect according to self-reported disability $(E S=0.67)$, preferably reached within 12 weeks of treatment. 


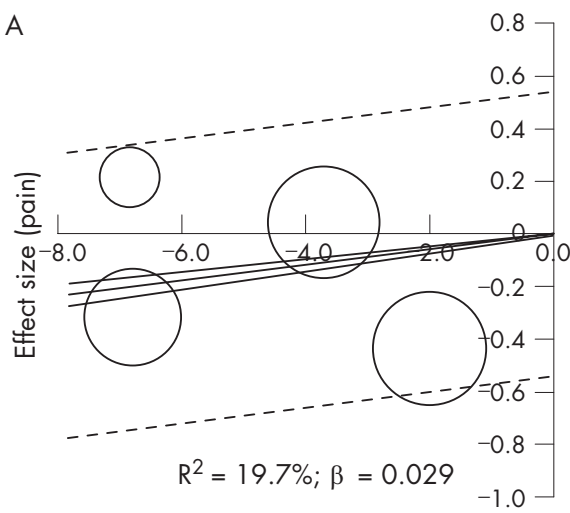

Magnitude: weight change ( $\%$ point)

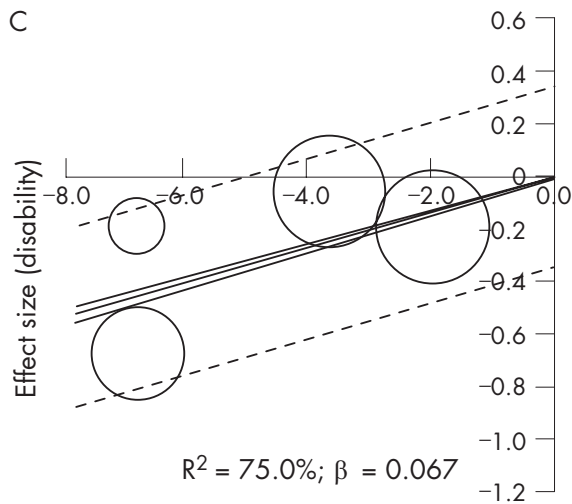

Magnitude: weight change (\% point)

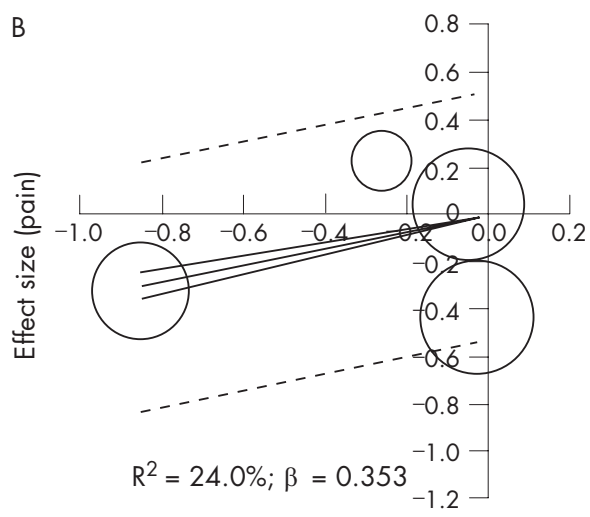

Intensity: weight change (\% point/week)

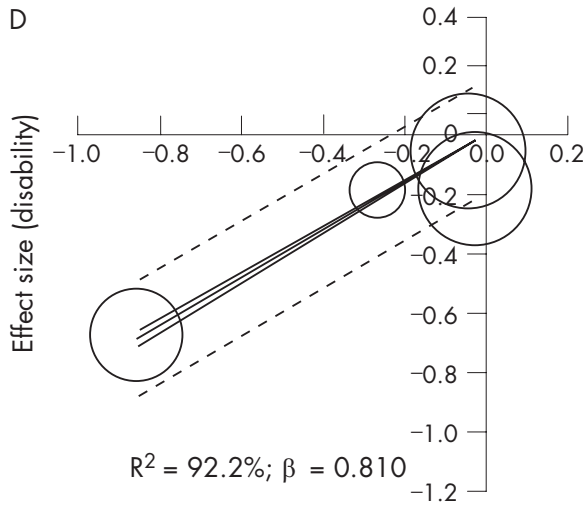

Intensity: weight change (\% point/week)
Figure 3 Weighted random effects metaregression analyses: effect sizes (ES) of the individual studies according to pain $(A, B)$ and self-reported disability $(C, D)$, following different rates of weight reductions $(A, C)$ at different intensities $(B, D)$; a decrease in ES would indicate clinical improvement. The area of each circle is inversely proportional to the random effects variance ${ }^{20}$ of the standardised mean difference; the fitted random-effects regression line is shown with $95 \%$ prediction intervals-indicating the degree of variance predicted by the weight loss magnitude and intensity.
A weakness of the present analysis was the few RCTs available for assessment, which emphasises the need for more and larger trials. Although only four studies were applicable in the analysis, based on the Jadad score, at least two of the studies were of top quality in this field.

In general, state-of-the-art weight loss policy among obesity specialists is that the overweight individual initiates a $10 \%$ reduction in body weight, which reduces multiple risk factors. ${ }^{45}$ With these guidelines, the effect of the weight loss may be achieved within a few months, resulting in a clinical ES larger than most non-operative treatments systematically reviewed, applying meta-analyses, ${ }^{66-69}$ and at least comparable to the possible effect of walking. ${ }^{70}$ In the present meta-analysis, it is obvious that the strategies applied in the individual RCTs combine great diversity in both magnitude and intensity of the (weight-reducing) dietary strategies. The "weight loss (3.7\%) regimen" used in the quantitatively largest trial ${ }^{58}$ would probably not be acknowledged as an anti-obesity approach ${ }^{71-73}$ following 18 months of treatment.

On the basis of the changes in pain scores reported by Messier et al, ${ }^{58}$ post hoc calculations from the data show that clinical efficacy can be documented only when weight loss is added to an exercise treatment $(\mathrm{ES}=0.44)$. We argue that the reason for this finding is a consequence of more attention, as has been observed in other patient groups with chronic pain. ${ }^{74}$ When compared with the control group, the dietary intervention failed regarding both weight reduction and pain relief despite a significant within-group 16\% pain reduction following $4.9 \%$ weight loss after 18 months of treatment. ${ }^{58}$ Interestingly, the exercise-only group-as the "only" of four different intervention groups-did not experience any significant pain reduction $(6 \%)$ in the study by Messier et al. ${ }^{58}$ By contrast, the healthy-lifestyle (control) group experienced a statistically

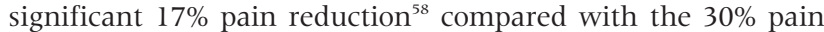
reduction observed following "diet plus exercise" ${ }^{58}$

In conclusion, professionals treating knee OA should bear a possible weight reduction in mind whenever a patient is significantly overweight. The patients ought to be encouraged to reduce their body weight, at least by $5 \%$ within a 20 -week period, to experience the symptomatic relief.

\section{ACKNOWLEDGEMENTS}

We acknowledge the personal and scientific support from Professor Bente Danneskiold-Samsøe, MD, Head of The Parker Institute, and Hans Lund, PT, PhD, The Parker Institute for providing excellent expertise about systematic reviews in general.

\section{Authors' affiliations}

Robin Christensen, Henning Bliddal, The Parker Institute, $\mathrm{H}: \mathrm{S}$

Frederiksberg Hospital, Frederiksberg, Denmark

Else Marie Bartels, Copenhagen University Library, Copenhagen, Denmark

Arne Astrup, The Department of Human Nutrition, The Royal Veterinary and Agricultural University, Frederiksberg, Denmark

Funding: This study was supported by grants from The Oak Foundation, $\mathrm{H}: \mathrm{S}$ Research Foundation, and The Danish Rheumatism Association.

Competing interests: None.

\section{REFERENCES}

1 Felson DT. Weight and osteoarthritis. Am J Clin Nutr 1996;63:430S-2S.

2 Arterburn DE, Crane PK, Sullivan SD. The coming epidemic of obesity in elderly Americans. J Am Geriatr Soc 2004;52:1907-12.

3 Flegal KM, Carroll MD, Ogden CL, Johnson CL. Prevalence and trends in obesity among US adults, 1999-2000. JAMA 2002;288:1723-7. 
4 WHO Technical Report Series. Obesity: preventing and managing the global epidemic. Report of a WHO Consultation on Obesity, No 894, June 1997. Geneva: World Health Organization, 2000.

5 WHO Technical Report Series. The burden of musculoskeletal conditions at the start of the new millennium. Report of the WHO Scientific Group, No 919, Geneva:World Health Organization, 2003.

6 Fontaine KR, Redden DT, Wang C, Westfall AO, Allison DB. Years of life lost due to obesity. JAMA 2003;289:187-93.

7 Woolf AD. The bone and joint decade 2000-2010. Ann Rheum Dis 2000;59:81-2.

8 Jordan KM, Arden NK, Doherty M, Bannwarth B, Bijlsma JW, Dieppe P, et al. EULAR recommendations 2003: an evidence based approach to the management of knee osteoarthritis. Report of a Task Force of the Standing Committee for International Clinical Studies Including Therapeutic Trials (ESCISIT). Ann Rheum Dis 2003;62:1145-55.

9 Bellamy N, Kirwan J, Boers M, Brooks P, Strand V, Tugwell P, et al. Recommendations for a core set of outcome measures for future phase III clinical trials in knee, hip, and hand osteoarthritis. Consensus development at OMERACT III. J Rheumatol 1997;24:799-802.

10 Eccles M, Freemantle N, Mason J. North of England evidence based guidelines development project: methods of developing guidelines for efficient drug use in primary care. BMJ 1998:316:1232-5.

11 Tugwell P, Shea B, Boers M, Brooks P, Simon L, Strand V, et al. Evidence-based rheumatology. London: BMJ books, 2004

12 Herbert RD, Bo K. Analysis of quality of interventions in systematic reviews. BMJ 2005;331:507-9.

13 Moher D, Cook DJ, Eastwood S, Olkin I, Rennie D, Stroup DF. Improving the quality of reports of meta-analyses of randomised controlled trials: the QUOROM statement. Quality of reporting of meta-analyses. Lancet 1999;354:1896-900.

14 Dougados M. Monitoring osteoarthritis progression and therapy. Osteoarthritis Cartilage 2004;12(Suppl A):S55-60.

15 Jadad AR, Moore RA, Carroll D, Jenkinson C, Reynolds DJ, Gavaghan DJ, et al. Assessing the quality of reports of randomized clinical trials: is blinding necessary? Control Clin Trials 1996;17:1-12.

16 Deeks JJ, Higgins JPT, Altman DG, ed. Analysing and presenting results. In: Higgins JPT, Green S, eds, Cochrane Handbook for Systematic Reviews of Interventions 4.2.5. [updated May 2005]. Chichester, UK: John Wiley \& Sons, 2005:97-166.

17 Cohen J. Statistical power analysis for the behavioral sciences. Lawrence Hillsdale, New Jersey: Earlbaum Associates, 1988.

18 The Cochrane Collaboration. RevMan Analyses. [Computer program], Review Manager (RevMan) 4.2. England: Oxford, 2003.

19 Normand SL. Meta-analysis: formulating, evaluating, combining, and reporting. Stat Med 1999; 18:321-59.

20 DerSimonian R, Laird N. Meta-analysis in clinical trials. Controlled Clin Trials 1986;88:177-88.

21 Cochran WG. Problems arising in the analysis of a series of similar experiments. $J$ R Stat Soc 1937;4:102-18.

22 Whitehead A, Whitehead J. A general parametric approach to the meta-analysis of randomized clinical trials. Stat Med 1991;10:1665-77.

23 Higgins JP, Thompson SG. Quantifying heterogeneity in a meta-analysis. Stat Med 2002;21:1539-58.

24 Thompson SG, Higgins JP. How should meta-regression analyses be undertaken and interpreted? Stat Med 2002;21:1559-73.

25 Felson DT, Goggins J, Niu J, Zhang Y, Hunter DJ. The effect of body weight on progression of knee osteoarthritis is dependent on alignment. Arthritis Rheum 2004;50:3904-9

26 ling SM, Xue QL, Simonsick EM, Tian J, Bandeen-Roche K, Fried LP, et al. Transitions to mobility difficulty associated with lower extremity osteoarthritis in high functioning older women: longitudinal data from the Women's Health and Aging Study II. Arthritis Rheum 2006;55:256-63.

27 Toda Y. The effect of energy restriction, walking, and exercise on lower extremity lean body mass in obese women with osteoarthritis of the knee. J Orthop Sci $2001 ; 6: 148-54$.

28 Thorpe PC, Isaac PF, Rodgers J. A controlled trial of mazindol (Sanjorex, Teronac) in the management of the obese rheumatic patients. Curr Ther Res Clin Exp 1975;17:149-55.

29 Williams RA, Foulsham BM. Weight reduction in osteoarthritis using phentermine. Practitioner 1981;225:231-2.

30 Barlow JH, Turner AP, Wright CC. A randomized controlled study of the Arthritis Self-Management Programme in the UK. Health Educ Res 2000;15:665-80.

31 Villareal DT, Banks M, Sinacore DR, Siener C, Klein S. Effect of weight loss and exercise on frailty in obese older adults. Arch Intern Med 2006;166:860-6.

32 Felson DT, Zhang Y, Anthony JM, Naimark A, Anderson JJ. Weight loss reduces the risk for symptomatic knee osteoarthritis in women. The Framingham Study. Ann Intern Med 1992;116:535-9.

33 Spector TD, Hart DJ, Doyle DV. Incidence and progression of osteoarthritis in women with unilateral knee disease in the general population: the effect of obesity. Ann Rheum Dis 1994;53:565-8

34 Cicuttini FM, Baker JR, Spector TD. The association of obesity with osteoarthritis of the hand and knee in women: a twin study. I Rheumatol 1996:23:1221-6.

35 Al Arfaj AS. Radiographic osteoarthritis and obesity. Saudi Med J 2002;23:938-42

36 Targonska-Stepniak B. Obesity and osteoarthritis. Reumatologia 2003;41:366-70

37 Manninen P, Riihimaki $\mathrm{H}$, Heliovaara $M$, Suomalainen $\mathrm{O}$. Weight changes and the risk of knee osteoarthritis requiring arthroplasty. Ann Rheum Dis 2004;63:1434-7.
38 Abu-Abeid S, Wishnitzer N, Szold A, Liebergall M. The influence of surgicallyinduced weight loss on the knee joint. Obes Surg 2005;15:1437-42.

39 Shafshak TS. Electroacupuncture and exercise in body weight reduction and their application in rehabilitating patients with knee osteoarthritis. Am J Chin Med 1995:23:15-25.

40 Focht BC, Ewing V, Gauvin L, Rejeski WJ. The unique and transient impact of acute exercise on pain perception in older, overweight, or obese adults with knee osteoarthritis. Ann Behav Med 2002;24:201-10.

41 Focht BC, Gauvin L, Rejeski WJ. The contribution of daily experiences and acute exercise to fluctuations in daily feeling states among older, obese adults with knee osteoarthritis. J Behav Med 2004;27:101-21.

42 Nicklas BJ, Ambrosius W, Messier SP, Miller GD, Penninx BW, Loeser RF, et al Diet-induced weight loss, exercise, and chronic inflammation in older, obese adults: a randomized controlled clinical trial. Am J Clin Nutr 2004:79:544-51.

43 Messier SP, Gutekunst DJ, Davis C, DeVita P. Weight loss reduces knee-joint loads in overweight and obese older adults with knee osteoarthritis. Arthritis Rheum 2005;52:2026-32

44 van Gool CH, Penninx BW, Kempen GI, Rejeski WJ, Miller GD, van Eijk JT, et al. Effects of exercise adherence on physical function among overweight older adults with knee osteoarthritis. Arthritis Rheum 2005;53:24-32.

45 Thorstensson CA, Roos EM, Petersson IF, Ekdahl C. Six-week high-intensity exercise program for middle-aged patients with knee osteoarthritis: a randomized controlled trial.[ISRCTN20244858]. BMC Musculoskelet Disord 2005;6:27.

46 Bennell KL, Hinman RS, Metcalf BR, Buchbinder R, McConnell J, McColl G, et al Efficacy of physiotherapy management of knee joint osteoarthritis: a randomised double blind, placebo controlled trial. Ann Rheum Dis 2005;64:906-12.

47 Huang $\mathrm{M}-\mathrm{H}$, Chen $\mathrm{C}-\mathrm{H}$, Chen T-W, Weng M-C, Wang W-T, Wang Y-L. The effects of weight reduction on the rehabilitation of patients with knee osteoarthritis and obesity. Arthritis Care Res 2000;13:398-405.

48 Li LC, Maetzel A, Pencharz JN, Maguire L, Bombardier C. Use of mainstream nonpharmacologic treatment by patients with arthritis. Arthritis Rheum 2004:51:203-9.

49 Focht BC, Rejeski WJ, Ambrosius WT, Katula JA, Messier SP. Exercise, selfefficacy, and mobility performance in overweight and obese older adults with knee osteoarthritis. Arthritis Rheum 2005;53:659-65.

50 Toda Y. A comparison of the efficacy of conservative therapies for obese patients with osteoarthritis of the knee. Ryumachi 2002;42:795-800.

51 Rejeski WJ, Focht BC, Messier SP, Morgan T, Pahor M, Penninx B. Obese, olde adults with knee osteoarthritis: weight loss, exercise, and quality of life. Health Psychol 2002;21:419-26.

52 Miller GD, Rejeski WJ, Williamson JD, Morgan T, Sevick MA, Loeser RF, et al The Arthritis, Diet and Activity Promotion Trial (ADAPT): design, rationale, and baseline results. Control Clin Trials 2003;24:462-80.

53 Miller GD, Nicklas BJ, Davis CC, Ambrosius WT, Loeser RF, Messier SP. Is serum leptin related to physical function and is it modifiable through weight loss and exercise in older adults with knee osteoarthritis? Int J Obes Relat Metab Disord 2004;28: 1383-90.

54 Christensen R, Stigsgaard L, Astrup AV, Bliddal H. Vaegttab som behandling af artrose i knaeled hos adipøse patienter-sekundærpublikation. [Weight loss as therapy of knee osteoarthritis in obese patients - secondary publication] Ugeskr Laeger 2005;23:2522-6.

55 van Gool CH, Penninx BW, Kempen GI, Miller GD, van Eijk JT, Pahor M, et al. Determinants of high and low attendance to diet and exercise interventions among overweight and obese older adults. Results from the arthritis, diet, and activity promotion trial. Contemp Clin Trials 2006;27:227-37.

56 Toda Y, Toda T, Takemura S, Wada T, Morimoto T, Ogawa R. Change in body fat, but not body weight or metabolic correlates of obesity, is related to symptomatic relief of obese patients with knee osteoarthritis after a weight control program. J Rheumatol 1998;25:2181-6.

57 Messier SP, Loeser RF, Mitchell MN, Valle G, Morgan TP, Rejeski WJ, et al. Exercise and weight loss in obese older adults with knee osteoarthritis: a preliminary study. J Am Geriatr Soc 2000;48:1062-72.

58 Messier SP, Loeser RF, Miller GD, Morgan TM, Rejeski WJ, Sevick MA, et al. Exercise and dietary weight loss in overweight and obese older adults with knee osteoarthritis: the Arthritis, Diet, and Activity Promotion Trial. Arthritis Rheum 2004;50:1501-10.

59 Christensen R, Astrup A, Bliddal H. Weight loss: the treatment of choice for knee osteoarthritis? A randomized trial. Osteoarthritis Cartilage 2005;13:20-7.

60 Thompson SG, Higgins JP. Treating individuals 4: can meta-analysis help target interventions at individuals most likely to benefit? Lancet 2005;365:341-6.

61 Bliddal H, Christensen R. The management of osteoarthritis in the obese patient: practical considerations and guidelines for therapy. Obes Rev 2006;7:323-31.

62 Law MR, Wald NJ, Rudnicka AR. Quantifying effect of statins on low density lipoprotein cholesterol, ischaemic heart disease, and stroke: systematic review and meta-analysis. BMJ 2003;326:1423

63 Johnson ES, Lanes SF, Wentworth III CE, Satterfield MH, Abebe BL, Dicker LW. A metaregression analysis of the dose-response effect of aspirin on stroke. Arch Intern Med 1999;159:1248-53.

64 Astrup A. Dietary approaches to reducing body weight. Baillieres Best Pract Res Clin Endocrinol Metab 1999;13:109-20.

65 National Institutes of Health. Clinical guidelines on the identification, evaluation, and treatment of overweight and obesity in adults - the evidence report. Obes Res 1998;6(Suppl 2):51S-209S

66 Towheed T, Maxwell L, Judd M, Catton M, Hochberg M, Wells G. Acetaminophen for osteoarthritis. Cochrane Database Syst Rev 2006; (1):CD004257.

67 Garner SE, Fidan DD, Frankish R, Maxwell L. Rofecoxib for osteoarthritis. Cochrane Database Syst Rev 2005;(1):CD005115. 
68 Fidelix T, Soares B, Trevisani VM. Diacerein for osteoarthritis. Cochrane Database Syst Rev 2006;CD005117.

69 Fransen M, McConnell S, Bell M. Exercise for osteoarthritis of the hip or knee. Cochrane Database Syst Rev 2003:3:CD004286.

70 Roddy E, Zhang W, Doherty M. Aerobic walking or strengthening exercise for osteoarthritis of the knee? A systematic review. Ann Rheum Dis 2005;64:544-8.

71 Bray GA, Greenway FL. Current and potential drugs for treatment of obesity. Endocr Rev 1999;20:805-75.
72 Padwal R, Li S, Lau D. Long-term pharmacotherapy for obesity and overweight. Cochrane Database Syst Rev 2003;(4):CD004094.

73 Li Z, Maglione M, Tu W, Mojica W, Arterburn D, Shugarman LR, et al. Metaanalysis: pharmacologic treatment of obesity. Ann Intern Med 2005;142:532-46.

74 Coxhead CE, Inskip H, Meade TW, North WR, Troup JD. Multicentre trial of physiotherapy in the management of sciatic symptoms. Lancet $1981 ; 1: 1065-8$

\section{Notice to EULAR 2006 delegates}

We hope you are enjoying your complimentary subscription to Annals of the Rheumatic Diseases - the EULAR Journal.

\section{ARE YOU PLANNING TO ATTEND EULAR 2007 IN BARCELONA?}

If you are not attending, your last free issue will be next month, May 2007.

Should you wish to continue receiving this important monthly journal you will need to subscribe.

We are pleased to offer EULAR 2006 delegates the chance to subscribe at the reduced rate of $€ 117(£ 79 / \$ 146)$ - a $60 \%$ saving off the usual personal subscription rate. This subscription includes both the print journal and access to ARD Online www.ard.bmj.com

You will shortly be receiving a subscription renewal notice. Please take the time to complete this and return it to BMJ Group to ensure continuing access to the journal.

EULAR 2007 delegates who wish to continue to enjoy a complimentary subscription will need to re-register; more details will be at the congress.

For more information email subscriptions@bmigroup.com 